www.jmscr.igmpublication.org

Impact Factor (SJIF): 6.379

Index Copernicus Value: 79.54

ISSN (e)-2347-176x ISSN (p) 2455-0450

crossrefDOI: https://dx.doi.org/10.18535/jmscr/v6i10.113

Journal Of Medical Science And Clinical Research

IGM Publication

An official Publication of IGM Publication

\title{
Role of Glucosamine Sulphate Supplements on Intra Ocular Pressure Given in Osteoarthritis Treatment-A Case Series
}

Authors

\author{
Dr N.Suhasini ${ }^{1}$, Dr M.Harini ${ }^{2 *}$, Dr T.Rajasekhar ${ }^{3}$ \\ ${ }^{1}$ M.S (Ophthalmology) FIGS, Asst. Prof. Ophthal GIMSR \\ ${ }^{2}$ M.S (E.N.T) Asst. Prof. ENT-GIMSR \\ ${ }^{3}$ DNB (Orthopaedics) Senior Resident Ortho-GIMSR
}

*Corresponding Author

Dr M. Harini

Flat No.302, Prathima Paradise Apartments, Opp. Gokul Park, Visakhapatnam-530002, India

\begin{abstract}
Aim: To analyze role of Glucosamine sulphate supplements given for treatment of Osteoarthritis on intraocular pressure.

Materials \& Methods: A case series of 100 patients who were diagnosed to have Osteoarthritis were selected and started on Glucosamine sulphate supplements in whom IOP was measured and analyzed for 1 year (From March 2017-March 2018) in GIMSR

Results: Out of 111 patients selected for study,11 patients were excluded as they were having high IOP, glaucomatous changes in fundus, corneal irregularities and postoperative cases

- $\quad$ Out of 100 patients 78 were females and 22 were males

- Most common age group being 40 to 60 years in both males and females

- IOP changes were more common in females than males

- IOP rise of $2 \mathrm{~mm} \mathrm{Hg}$ was identified in both eyes after a period of 1 year in considerable no of patients

Conclusions: Out of total number of 20,000 patients attended Orthopaedics department from March 2017 to March 2018 in GIMSR, 5000 patients complained of kneeproblem. Among them 100 patients were selected for the study. Patients with previous history of glaucoma, previous surgeries, fundus changes, not willing for regular follow up and corneal abnormalities were excluded from the study. Measurement of IOP was done in all 100 patients before starting of Glucosamine sulphate and patients were instructed to come for regular follow-ups 5 times at 3 months interval.

- In our study major proportion of patients were females constituting78\% compared to males who were only $22 \%$.

- Commonest age group effected both in males and females was 40-60 years.

- Normal range of 10 to $20 \mathrm{~mm} \mathrm{Hg}$ IOP was seen in almost $90 \%$ of patients.

- After administration of Glucosamine for a period of 3 months not much IOP change is noticed

- After 6 months 34\% of patients have shown $2 \mathrm{~mm} \mathrm{Hg}$ increase in IOP in both eyes but were within normal range

- Thus Glucosamine sulphate can be used in Osteoarthritis with regular monitoring of IOP and considered to be relatively safe.

Keywords: Glaucoma, intra ocular pressure, Osteoarthritis.
\end{abstract}




\section{Introduction}

An amino monosaccharide Glucosamine is an essential constituent of cartilage. Glucosamine sulphate supplements widely used for Osteoarthritis treatment appear to increase IOP, researchers say. Though evidence is lacking that it can improve symptoms of Osteoarthritis, radiographic studies have shown that it slows joint space width loss and hence appears to be safe \& popular as a treatment. However Glucosamine is also abundant in corneal stroma and plays a role in morphology and function of the trabecular meshwork.

One small retrospective study showed an association between Glucosamine supplement usage and IOP. Glycosaminoglycans constitute ground substance for outermost part of the trabecular meshwork. Long, flexible chains of GAG interact with each otherto form a system of entangled polyanionic macromolecules which act like a gel and contribute to outflow resistance. Accumulated GAG in ground substance of trabecular meshwork outflow pathways and increased constriction of the trabecular spaces could explain rise in IOP seen with even short courses of steroid treatment.

In this study our aim was to study role of Glucosamine supplements in Osteoarthritis patients on IOP among patients attending Orthopaedics department in GIMSR. This is a prospective study conducted over a period of 1 year from March 2017 to March 2018. These patients were kept on $750 \mathrm{mg}$ Glucosamine sulphate supplements thrice a day and were referred to Ophthalmology department. Each patient was evaluated fully and IOP was measured in 5 consecutive visits :On the day of starting treatment, 3 months ,6months, 9months and 1year duration. Patients were counselled regarding usage of drug and necessity of review visits. So whoever willing to come for 5 follow ups were taken and IOP measurement was done using Goldmann applanation tonometry.

\section{Aims \& Objectives}

To find out role of Glucosamine sulphate supplements given in Osteoarthritis patients on IOP attending outpatient Orthopaedics and Ophthalmology departments in GIMSR

\section{Materials \& Methods}

This is a prospective study conducted over a period of one year from March 2017 to March 2018 in GIMSR

Out of all patients attending Orthopedics department with osteoarthritis, 111 patients were selected and started on Glucosamine sulphate 750 $\mathrm{mg}$ thrice a day and were sent to Ophthalmology department for evaluation before starting treatment .The patients were asked for follow up in 5 consecutive visits. Patients already diagnosed with more IOP and fundus changes were excluded and 100 patients were selected finally for study.

\section{Inclusion Criteria}

- Patients of all age groups on Glucosamine supplements.

- Patients giving consent for the study

- Patients willing to come for regular follow up.

\section{Exclusion Criteria}

- Patients not giving consent for study

- Patients already having raised IOP.

- Patients not coming for regular follow up.

- Patients with fundus changes.

- Post operative patients

- Patients with corneal irregularities and dystrophies

\section{Observations}

From March 2017 to March 2018 total number of patients attended Orthopaedics department were 20000, out of which 5000 patients complained of knee problem. All patients were sent to Ophthalmology department. Out of them 100 patients were finally selected and started on Glucosamine sulphate drug. 
Out of 100 patients selected for the study 78 were females (78\%) and 22 were males $(22 \%)$

Table 1: shows sex distribution in the study revealing females were more effected than males

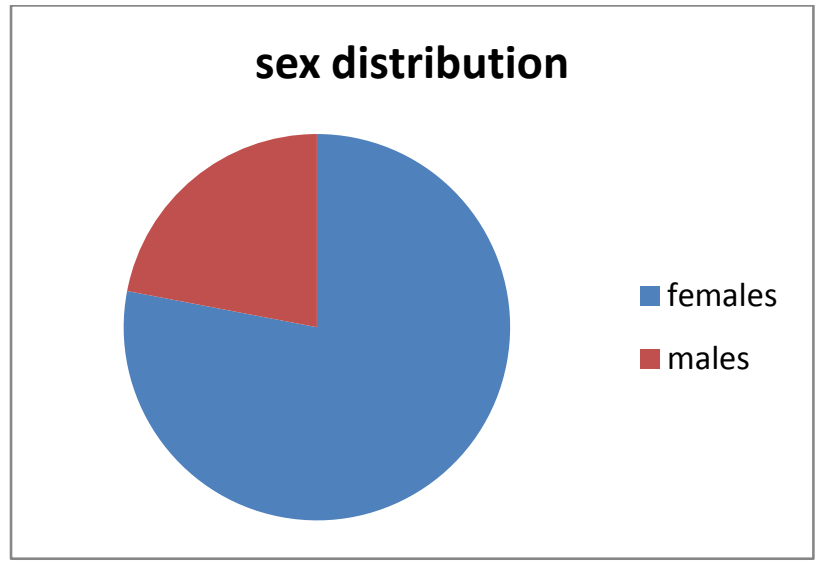

Table 2: shows that major age group which was effected in both sexes was 40 -60 years constituting $43 \%$ in females and $14 \%$ in males

\begin{tabular}{|l|c|c|c|c|}
\hline Age group & Females & Males & Total & Percentage \\
\hline $20-40$ yrs & 15 & 1 & 16 & $16 \%$ \\
\hline $40-60$ yrs & 43 & 14 & 57 & $57 \%$ \\
\hline$>60$ yrs & 20 & 7 & 27 & $27 \%$ \\
\hline Total & 78 & 22 & 100 & $100 \%$ \\
\hline
\end{tabular}

Table 3: shows IOP recorded in both eyes before administration of drug (Normal IOP measurement is around 10 to $20 \mathrm{~mm} \mathrm{Hg}$ )

\begin{tabular}{|l|c|c|}
\hline \multicolumn{1}{|c|}{ IOP } & Right eye & Left eye \\
\hline$>10 \mathrm{~mm} \mathrm{Hg}$ & 1 & 1 \\
\hline $10-15 \mathrm{~mm} \mathrm{Hg}$ & 80 & 87 \\
\hline $15-20 \mathrm{~mm} \mathrm{Hg}$ & 15 & 8 \\
\hline $20-25 \mathrm{~mm} \mathrm{Hg}$ & 2 & 3 \\
\hline $25-30 \mathrm{~mm} \mathrm{Hg}$ & 2 & 1 \\
\hline$>30 \mathrm{~mm} \mathrm{Hg}$ & - & - \\
\hline Total & 100 & 100 \\
\hline
\end{tabular}

Table 4: Results showing rise in IOP after usage of drug for a period of 1 year.

(There was definitely rise but within normal range of 10 to $20 \mathrm{~mm} \mathrm{Hg}$ )

\begin{tabular}{|l|c|c|}
\hline \multicolumn{1}{|c|}{ IOP } & Right eye & Left eye \\
\hline$>10 \mathrm{~mm} \mathrm{Hg}$ & - & - \\
\hline $10-15 \mathrm{~mm} \mathrm{Hg}$ & 50 & 70 \\
\hline $15-20 \mathrm{~mm} \mathrm{Hg}$ & 46 & 26 \\
\hline $20-25 \mathrm{mmHg}$ & 3 & 3 \\
\hline $25-30 \mathrm{~mm} \mathrm{Hg}$ & 1 & 1 \\
\hline$>30 \mathrm{~mm} \mathrm{Hg}$ & - & - \\
\hline Total & 100 & 100 \\
\hline & & \\
\hline
\end{tabular}

Table 5: shows IOP changes (Among 100 patients in $34 \%$ around $2 \mathrm{mmHg}$ rise of IOP noted)

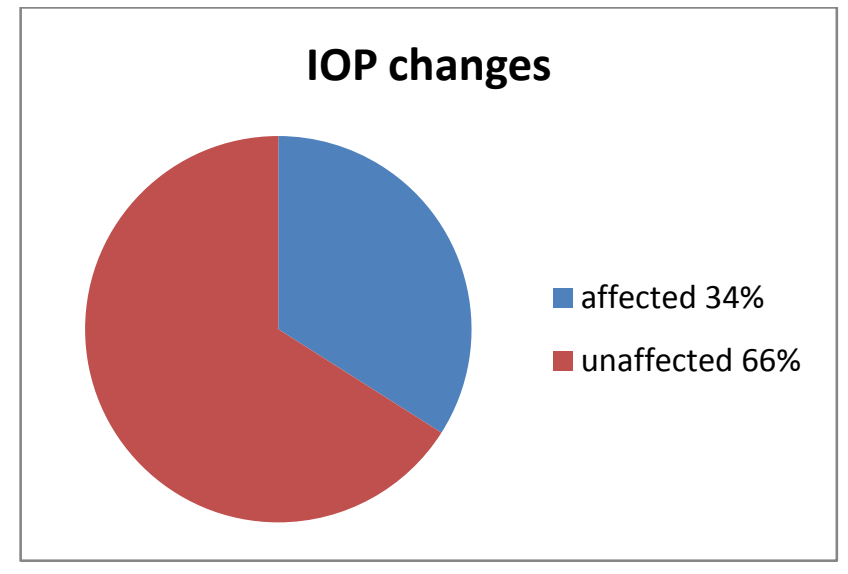

\section{Discussion}

Glycosaminoglycans are the most abundant heteropolysacchride in the human eye.

They are key constituent of the extracellular matrix and act as a filler substance between cells and fibers in the tissues. Normal aqueous out flow is affected by GAG content which acts like a gel and are important contributor for outflow resistance.

In our prospective study which was conducted in GIMSR for a period of 1 year from March 2017 to March 2018 around 100 patients were diagnosed to have Osteoarthritis and were put on glucosamine sulphate $750 \mathrm{mg}$ thrice a day.

IOP was measured in these 100 patients in about 5 consecutive visits 3 months apart each and IOP rise was checked. In initial visits there was not any IOP changes but around 6 months duration $34 \%$ of patients have shown $2 \mathrm{~mm} \mathrm{Hg}$ IOP rise where as $66 \%$ of patients did not show any IOP changes. Among $34 \%$ of patients commonest age group to show changes in IOP was 40 to 60 years and younger generation did not show much changes. This results corresponds to study conducted by Murphy et al stating that younger generation were not much affected.

In our study there was not much rise of IOP but in the study of Murphy et al they have stated that there was significant rise in IOP. Our results of 2 $\mathrm{mm} \mathrm{Hg}$ in both eyes rise of IOP corresponds to 
clinical trial of $\mathrm{H}$. Esfandiari et al and Larid Harrison study.

Commonest age group effected was around 40 to 60 yrs in our study but study conducted by Larid Harrison et al was >60 yrs. Binninger et $a l$ showed that exogenous GAG stimulate cultured human trabecular meshwork cells to produce more GAG as positive feedback mechanism.

\section{Conclusion}

Out of total number of 20000 patients attended Orthopaedics department from March 2017 to March 2018,5000 patients complained of knee problem. Among them 100 patients were selected for the study. Patients with previous history of glaucoma, previous surgeries, fundus changes, not willing for regular follow up and corneal abnormalities were excluded from the study.

Measurement of IOP was done in all 100 patients before usage of Glucosamine sulphate and patients were instructed to come for regular follow ups 3 monthly.

- In our study major proportion of patients were females constituting $78 \%$ compared to males who were only $22 \%$.

- Commonest age group effected both in males and females was 40-60 years .

- Normal range of 10 to $20 \mathrm{~mm} \mathrm{Hg}$ IOP was seen in almost $90 \%$ of the patients

- After administration of drug for a period of 3 months not much IOP change was noticed

- After 6 months 34\% of patients have shown $2 \mathrm{~mm} \mathrm{Hg}$ increase in IOP but were within the normal range

- Thus glucosamine sulphate can be used in Osteoarthritis with regular monitoring of IOP and considered to be relatively safe.

\section{References}

1. Murphy RK, Ketzler L, Rice RD, Johnson SM, Doss MS, Jaccoma EH. Oral glucosamine supplements as a possible ocular hypertensive agent. JAMA Ophthalmol 2013; 131:955-957. [PubMed]
2. Binninger EA, Schachtschabel DO, Rohen JW. Exogenous glycosaminoglycans stimulate hyaluronic acid synthesis by cultured human trabecular-meshwork cells. Exp Eye Res 1987; 45: 169 177. [PubMed]

3. Deal CL, Moskowitz RW. Nutraceuticals as therapeutic agents in osteoarthritis. The role of glucosamine, chondroitin sulfate and collagen hydrolysate. Rheum Dis Clin North Am 1999; 25: 379-395. [PubMed]

4. Pavelka K, Gatterova J, Olejarova M, Machacek S, Giacovelli G, Rovati LC. Glucosamine sulfate use and delay of progression of knee osteoarthritis: a 3year, randomized, placebo-controlled, double-blind study. Arch Intern Med 2002; 162: 2113-2123. [PubMed]. 
